\title{
A Model and Experimental Validation to Predict Heating Rates for Overlap Between Ferrite Recrystallization and Austenite Transformation in Dual Phase Steel Manufacture
}

\author{
BHARATH BANDI, ${ }^{1}$ JOOST VAN KREVEL, ${ }^{2}$ NUMAN ASLAM,${ }^{3}$ and \\ PRAKASH SRIRANGAM ${ }^{1,4}$ \\ 1.-Warwick Manufacturing Group (WMG), University of Warwick, Coventry CV4 7AL, UK. \\ 2.--Research and Development, Tata Steel, 3H36, PO box 10000, 1970 CA Ijmuiden, \\ The Netherlands. 3.-Research and Development, Tata Steel, Coventry CV4 7AL, UK. \\ 4.-e-mail: p.srirangam@warwick.ac.uk
}

A systematic theoretical and experimental study has been conducted to predict the heating rates required to obtain a pre-defined percentage of overlap between the ferrite recrystallization process and the austenite formation process in dual phase steel manufacture. Isothermal recrystallization kinetics for three different cold-reduced low-carbon micro-alloyed steels $(50 \%, 60 \%$, and $75 \%$ ) with ferrite-pearlite-bainite initial microstructures was evaluated. Using various experimentally determined rate kinetic constants and critical temperatures, a continuous heating rate model which predicts the heating rate required for a predefined amount of overlap was successfully developed. The model predicted the heating rates required for a predefined $1 \%, 15 \%, 34 \%$, $67 \%, 88 \%$ and $99 \%$ of overlap to be $0.2^{\circ} \mathrm{C} / \mathrm{s}, 0.9^{\circ} \mathrm{C} / \mathrm{s}, 1.8^{\circ} \mathrm{C} / \mathrm{s}, 7^{\circ} \mathrm{C} / \mathrm{s}, 50.5^{\circ} \mathrm{C} / \mathrm{s}$ and $511^{\circ} \mathrm{C} / \mathrm{s}$, respectively. The experimentally determined recrystallization percentage values validated the predicted heating rates.

\section{INTRODUCTION}

In recent decades, the automotive industry has been able to manufacture vehicles with high crash safety and better fuel efficiency thanks to the rapid development of advanced high-strength steels (AHSS). ${ }^{1}$ Amongst these, dual phase steels (DP), one of the most prominent materials, is used as safety and structural components in modern-day automotive vehicles due to its excellent combination of strength and formability. ${ }^{2}$ This combination of high strength and good formability of DP steels is attributed to its composite-like microstructure, comprising a soft ferrite matrix with hard martensite, bainite $^{3}$ and/or optionally retained austenite islands. ${ }^{4}$ More specifically, the mechanical properties of these steels depend on the inherent microstructural features such as ferrite/ bainite/martensite morphologies, ${ }^{5}$ and their respective volume fractions, ${ }^{6}$ martensite carbon content, ${ }^{7}$ ferrite precipitate distribution, ${ }^{8}$ ferrite dislocation density $^{9}$ and texture, etc. ${ }^{3}$ These room-temperature microstructural features are in turn directly influenced by the composition, distribution and morphology of the austenite phase formed (between $\mathrm{A}_{\mathrm{c} 1}$ and $\mathrm{A}_{\mathrm{c} 3}$ temperatures) during the heating step of the continuous annealing process. ${ }^{10}$ Additionally, during this heating step, other high-temperature mechanisms, such as ferrite recovery, recrystallization, and cementite spheroidization, etc., occur, mostly consequently but also concurrently, with the austenite formation step and have a major influence on it. ${ }^{11}$ The amount of overlap between these thermally activated processes strongly depend on the initial microstructures, stored deformation energy, type and alloy contents and the employed heating rates during the continuous annealing process. ${ }^{12}$

In the past decade, researchers have employed high heating rates ${ }^{13}$ to increase the percentage of this overlap and therefore increase the complex interplay between these mechanisms, and consequently achieved interesting results such as ferrite $^{14}$ and prior austenite ${ }^{15}$ grain refinement, ${ }^{16}$ increase in martensite volume fraction, ${ }^{17}$ change in ferrite/martensite morphology, variation in 
texture evolution, ${ }^{18,19}$ texture memory effect, ${ }^{20}$ increase in ultimate tensile strength and enhanced $\%$ elongation, ${ }^{21}$ etc. However, the chosen heating rates were mostly arbitrary and inconsistent, as the sole aim of the most researchers was to choose as high heating rate as possible to achieve maximum overlap. For instance Huang et al., chose a heating rate of $100^{\circ} \mathrm{C} / \mathrm{s}$ for $55 \%$ cold-rolled Fe-C-Mn-Mo ferrite-pearlite steel. ${ }^{11}$ Azizi-Alizamini et al., ${ }^{10}$ heated using a rate of $900^{\circ} \mathrm{C} / \mathrm{s}$ for their $80 \%$ coldrolled Fe-C-Mn ferrite-pearlite steel. Both Bellavoine et al., ${ }^{22}$ and Philippot et al., ${ }^{23}$ chose $10^{\circ} \mathrm{C} / \mathrm{s}$ for an initial microstructure of $50 \%$ cold-rolled ferritemartensite Fe-C-Mn-Nb-Ti steels. Massardier et al., used heating rates ranging from $20^{\circ} \mathrm{C} / \mathrm{s}$ to $1000^{\circ} \mathrm{C} / \mathrm{s}$ for $75 \%$ cold-rolled Al-killed low-carbon steels. ${ }^{24}$ Similarly, Kulakov et al., ${ }^{25}$ chose a heating rate of $100^{\circ} \mathrm{C} / \mathrm{s}$ for $50 \%$ cold-rolled materials of three different initial microstructures. These wide ranges of heating rates produce different percentages of overlap, which makes the comparison between the various studies ineffective. Moreover, the increase in the amount of stored deformation energy induced by a higher cold reduction (CR) increases the recrystallization kinetics, ${ }^{26}$ which in turn can decrease the overlapping process. In contrast to this, the addition of alloying elements retards the recrystallization process either by solute drag effect or pinning action, ${ }^{27}$ thereby enhancing the overlapping process. Hence, to study the effect of the percentage of overlap on the various initial microstructures, $\mathrm{CRs}$, and alloying additions, the amount of overlap should be identical. However, distinct heating rates need to be employed to achieve the same amount of overlap for different materials. Rather than applying heating rates randomly, this can only be possible by carefully selecting the heating rates such that a predefined amount of overlap is achieved.

Therefore, to develop a deeper understanding of this complex overlapping process between ferrite recrystallization and austenite formation, and to have a proper comparison between different initial materials, heating rates should be selected systematically where the degree of overlap is methodically monitored. In this work, a model is developed to predict the heating rate required for a pre-defined amount of overlap for a given material. Also, heat treatments were carried out to study the recrystallization kinetics to validate the predicted heating rates.

\section{EXPERIMENTAL PROCEDURE}

\section{Materials}

The present study was conducted on low-carbon cold-rolled steels with an initial ferrite-pearlitebainite hot-rolled (HR) microstructure. The chemical composition of the as-received steel is Fe-0.14C2.1Mn-0.37Si-0.06V (wt.\%). Vanadium was added to retard the ferrite recrystallization kinetics. To study the effect of stored deformation energy on the heating rate required for a given percentage of overlap, the as-received $2-\mathrm{mm} \mathrm{HR}$ and pickled material, from the Tata Steel pickling plant, was cold-rolled with a Hille-Müller laboratory cold-rolling mill to three different CRs of $50 \%$ ( $1 \mathrm{~mm}), 60 \%$ $(0.8 \mathrm{~mm})$ and $75 \%(0.5 \mathrm{~mm})$.

\section{Heat Treatments}

Full sheet thickness samples were cut from the three $\mathrm{CR}$ steels into $10 \times 4 \mathrm{~mm}$ dimensions with the transverse direction aligned with the longitudinal dimension. A Bähr Dilatometer 805 A/D was used to perform all the heat treatments, with the simultaneous dilation measurements taken along the longitudinal direction. Two types of heat treatments were employed in this study:

1) Ramp and hold type of heat treatments were carried out to evaluate the Johnson-Mehl-AvramiKolmogorov (JMAK) parameters for all the three CR steels. A heating rate of $50^{\circ} \mathrm{C} / \mathrm{s}$ was employed for all these tests. The holding temperatures for both $50 \%$ and $60 \% \mathrm{CRs}$ were chosen as $650^{\circ} \mathrm{C}$ and $675^{\circ} \mathrm{C}$, whereas $625^{\circ} \mathrm{C}$ and $650^{\circ} \mathrm{C}$ were chosen for the $75 \%$ $\mathrm{CR}$ steel. The holding times ranged from $1 \mathrm{~s}$ to $900 \mathrm{~s}$ before helium gas quenching $\left(-150^{\circ} \mathrm{C} / \mathrm{s}\right)$.

2) Continuous type of heat treatments were carried out to evaluate the recrystallization start temperatures (RxT) and austenite start temperatures $\left(\mathrm{A}_{\mathrm{c} 1}\right)$ for all the three CRs. In these tests, the dilatometry samples were continuously heated at four different heating rates $\left(1^{\circ} \mathrm{C} / \mathrm{s}, 10^{\circ} \mathrm{C} / \mathrm{s}, 100^{\circ} \mathrm{C} / \mathrm{s}\right.$, and $\sim 500^{\circ} \mathrm{C} / \mathrm{s}$ ) to a temperature higher than $900^{\circ} \mathrm{C}$, and the deviations in the dilation data were precisely recorded to determine their corresponding $\mathrm{RxT}$ and $\mathrm{A}_{\mathrm{c} 1}$ temperatures. To validate the $\mathrm{RxT}$ temperatures obtained from the dilation curves, quench heat treatment tests were carried out. Here, the $\mathrm{CR}$ steels were heated at $10^{\circ} \mathrm{C} / \mathrm{s}$ to the corresponding $\mathrm{RxT}$ and $\mathrm{Rx} \mathrm{T}+5^{\circ} \mathrm{C}$ temperatures followed by quenching to room temperature.

\section{Characterization}

Micro-Vicker's hardness measurements were carried out for the as-received and the heat-treated materials using a Wilson hardness testing machine with a load of 500 gat a dwell time of $10 \mathrm{~s}$. At least 15 hardness values were recorded for each measurement. The fraction of recrystallization (X) was calculated using the following formula:

$$
X=\frac{H_{0}-H}{H_{0}-H_{\mathrm{c}}}
$$

where $H_{0}$ is the hardness value of the cold rolled material, $H$ is the hardness value of the annealed material and $H_{\mathrm{c}}$ is the hardness value of the fully recrystallized material.

For microstructural analysis, the samples were cut into the rolling plane. Following the standard 
procedures, the mounted samples were mechanically ground and polished in an automatic polisher. After cleaning and drying, the samples were etched for $10 \mathrm{~s}$ using $2 \%$ Nital solution. The microstructural images of the samples were taken using a FEG JEOL 7800F-SEM equipped with secondary electron (SE) detector and electron back scatter diffraction detector (EBSD).

Using the obtained JMAK values, a continuous heating rate model was generated in order to determine the percentage of recrystallization before the onset of austenite formation for a given heating rate. The degree of recrystallization happening before austenite formation in all the three CRs for all the four different heating rates $\left(1^{\circ} \mathrm{C} / \mathrm{s}, 10^{\circ} \mathrm{C} / \mathrm{s}\right.$, $100^{\circ} \mathrm{C} / \mathrm{s}$, and $500^{\circ} \mathrm{C} / \mathrm{s}$ ) were calculated and compared. Using the RxT and $\mathrm{A}_{\mathrm{c} 1}$ temperature trends obtained from the continuous heat treatments, the model calculates the specific heating rates required for various percentages of overlap in the CR 50\% material. The true percentages of overlaps were calculated for the samples heat-treated at the same heating rates predicted by the model.

\section{RESULTS AND DISCUSSION}

\section{Initial Cold Rolled Material}

Figure 1 shows the microstructures of the initial $\mathrm{HR}$ and cold-rolled materials with their corresponding hardness values. The ferrite grain size in the HR steel was found to be $7 \mu \mathrm{m}$ and its pearlite volume percent was found to be $21 \%$. It can be clearly seen that the amount of deformation in the ferrite grains and its corresponding aspect ratios increases with increase in CR. Moreover, it can be seen that the fragmented cementite particles are aligned along the rolling direction on the deformed ferrite grains. The increase in the hardness values with the increase in CR (as shown in Fig. 1e) indicates the increase in the stored deformation energy in the material. This can be attributed to the increase in dislocation density and the residual stresses with the increase in the CR in the cold-rolled material. ${ }^{28}$

\section{Determination of JMAK Coefficients}

The recrystallization fractions for the three cold reductions were calculated using Eq. 1. Figure 2 shows the increase in the fraction of recrystallization with the increase in the holding times at $650^{\circ} \mathrm{C}$ and $675^{\circ} \mathrm{C}$ for CR $50 \%$. Recrystallization being a thermally activated process, the fraction of recrystallization shifts towards a lower holding time with the increase in the holding temperature. The increase in the hardness values due to carbon dissolution during annealing was considered negligible compared to the decrease in hardness due to the ongoing recrystallization process. In addition, the decrease in hardness due to grain growth after recrystallization is negligible compared to the hardness decrease related to recrystallization. Figure 3a compares the evolution of recrystallization at $650^{\circ} \mathrm{C}$ for the three CRs. It can be clearly seen that the kinetics of the recrystallization process is faster for a larger cold-rolling reduction. This is due to the increase in the stored deformation energy with the increase in the $\mathrm{CR}$ and therefore the increase in the driving force for the recrystallization process. ${ }^{26} \mathrm{At}$ the same time, the increase in the CR increases the grain boundary area by elongating the grains,
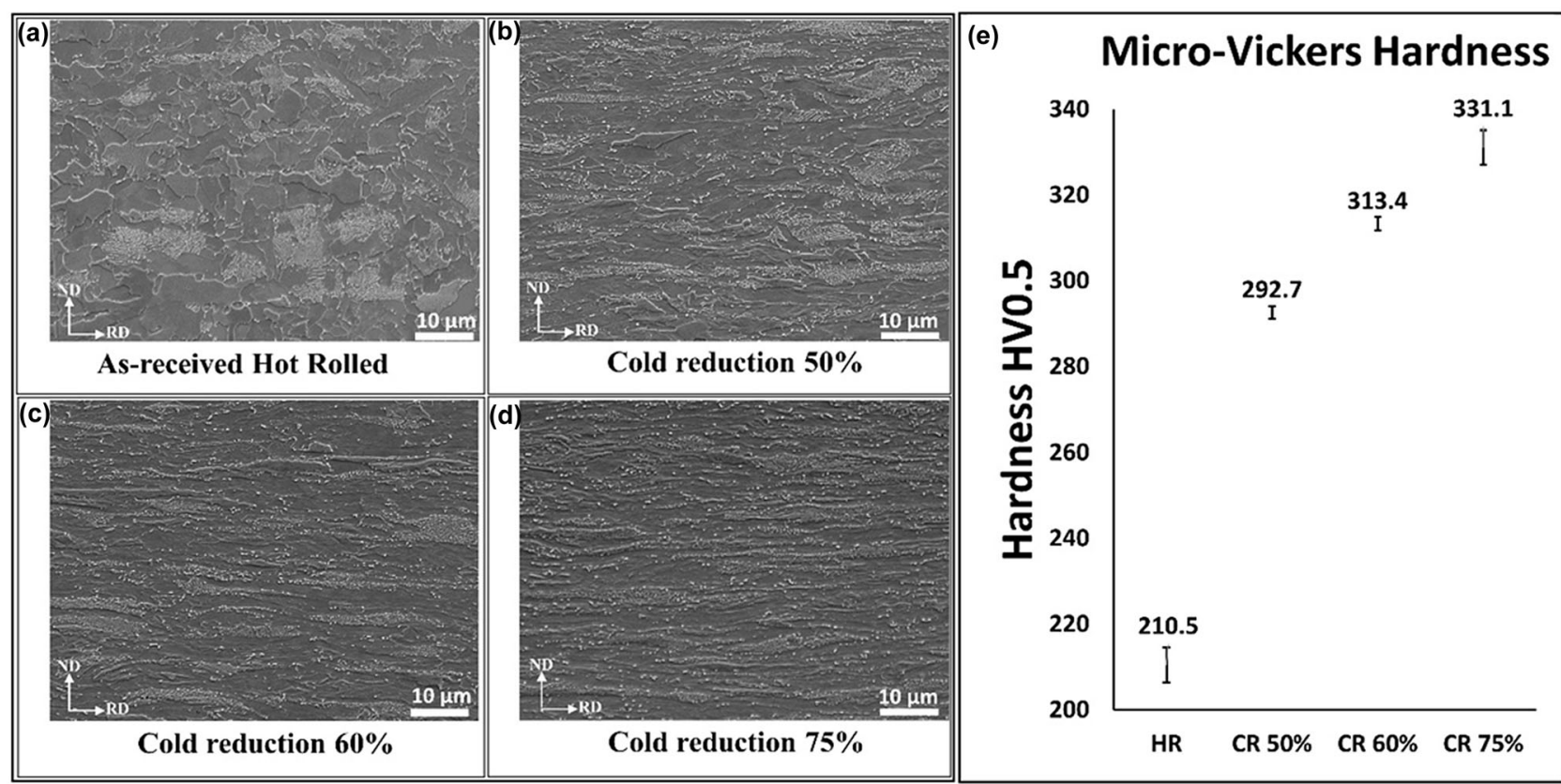

Fig. 1. (a-d) SEM microstructural images of (a) as-received HR, (b) CR 50, (c) CR 60 and (d) CR 75 steels; (e) comparison of Micro-Vicker's hardness values for the hot-rolled and cold-rolled steels. 
thereby providing more nucleating sites for the recrystallization process. ${ }^{29}$ Figure $3 \mathrm{~b}$ and $\mathrm{c}$ shows the SEM micrographs of CR 50\% and CR 75\%, heattreated at $650^{\circ} \mathrm{C}$ for $900 \mathrm{~s}$ and $300 \mathrm{~s}$, respectively. It can be clearly seen that the type of recrystallized grains is almost the same, even though the holding times for both the steels are different. However, cementite spheroids are coarse in CR 50\% steel, whereas cementite spheroids are fine in CR $75 \%$ steel and are still aligned in the original segregation bands.

Using the above recrystallization fractions, the recrystallization kinetics can be suitably fit into the JMAK equation shown in Eqs. 2 and $3{ }^{30}$ This equation defines the fraction of recrystallization $(X)$ as a function of time $(t)$ and absolute temperature $(T)$ :

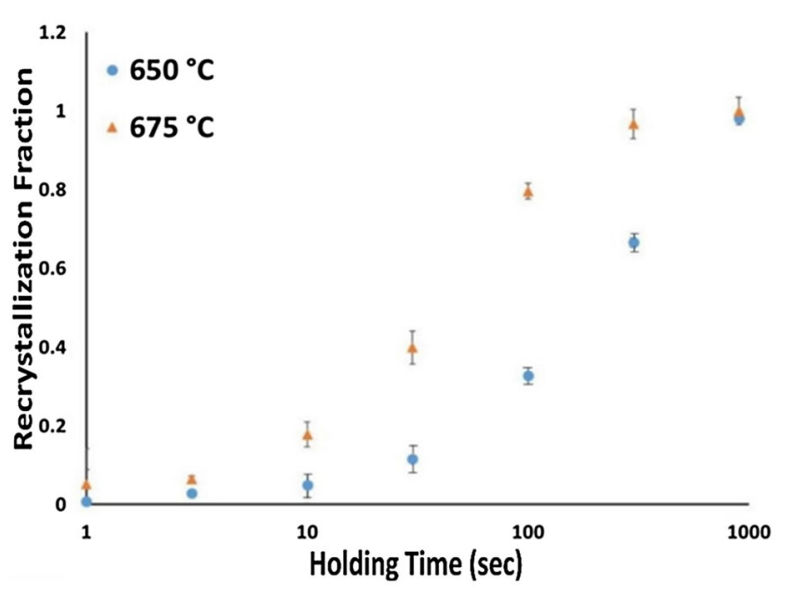

Fig. 2. Progress of recrystallization during isothermal holding at $650^{\circ} \mathrm{C}$ and $675^{\circ} \mathrm{C}$ for CR 50 steel.

$$
\begin{aligned}
& X=1-\exp ^{-b t^{n}} \\
& b=b_{0} \exp ^{-Q / R T}
\end{aligned}
$$

Here, $Q$ is the activation energy, $R$ is the universal gas constant and $n, b_{0}$ are the JMAK parameters.

To calculate the values of $n$ and $b$, the JMAK equation was modified as shown in Eq. 4. The slope and intercept of the straight line obtained from the plotted graph gives the $\mathrm{n}$ and $\mathrm{b}$ values, respectively.

$$
\ln (-\ln (1-X))=n \ln t+\ln b
$$

Figure 4a shows the plotted graph of Eq. 4 for CR 50 steel isothermally held at $650^{\circ} \mathrm{C}$ and $675^{\circ} \mathrm{C}$. By averaging the value of the slopes, $n$ value was determined to be 0.87. By applying Eq. 3, the activation energy $\mathrm{Q}$ was found to be $339 \mathrm{~kJ} / \mathrm{mole}$. This value is very high compared to the selfdiffusion activation energy of $251 \mathrm{~kJ} / \mathrm{mol}$ for bcciron. ${ }^{31}$ This increase in the activation energy can be attributed to the retarding effect of alloying additions on the recrystallization process either by solute drag effect or pinning action. ${ }^{32}$ Similarly, the value of the constant $b_{0}$ was found to be $1.3 \times 10^{17} / \mathrm{s}$ which matches with the values obtained in the literature. Using these JMAK parameters, the JMAK equation (Eq. 2) is fitted with actual measured values and is shown in Fig. 4b. The JMAK model fits with the actual measured values with slight deviations which is expected in the continuously heated material.

JMAK parameters for CR $60 \%$ and $75 \%$ steels were also determined using Eq. 4. Figure 5a shows the comparison of the linearized JMAK plots (Eq. 4) for all the CR steels. The obtained JMAK parameters for all the steels are shown in

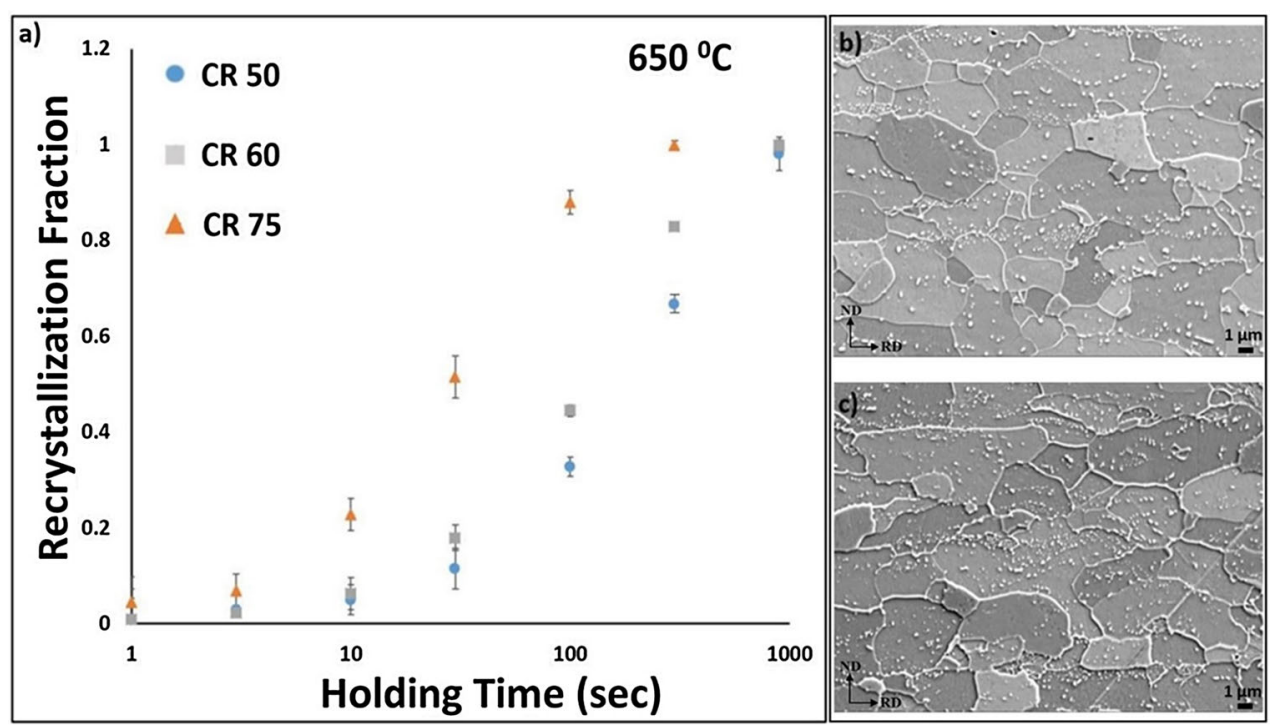

Fig. 3. (a) Progress of recrystallization during isothermal holding at $650^{\circ} \mathrm{C}$ for $\mathrm{CR} 50,60$ and 75 steels, (b, c) SEM micrographs of (b): $\mathrm{CR} 50$, and (c) $\mathrm{CR} 75$ heat-treated at $650^{\circ} \mathrm{C}$ for $900 \mathrm{~s}$ and $300 \mathrm{~s}$, respectively. 

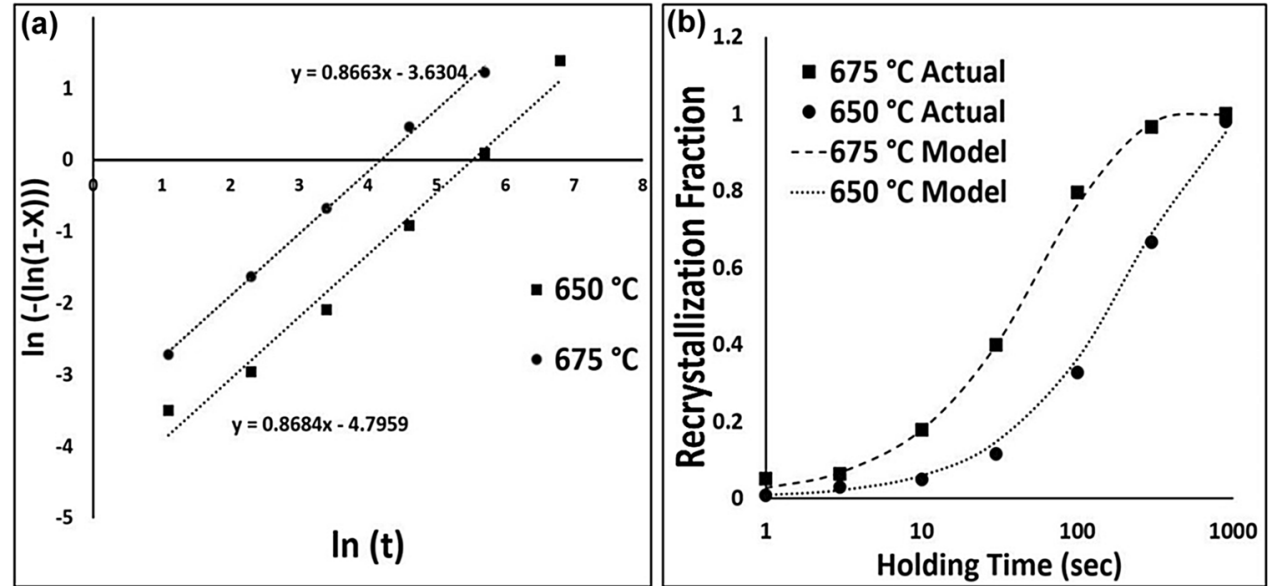

Fig. 4. (a) Linearized JMAK plot at $650^{\circ} \mathrm{C}$ and $675^{\circ} \mathrm{C}$. (b) JMAK model fit with the experimental recrystallized values at $650^{\circ} \mathrm{C}$ and $675^{\circ} \mathrm{C}$ for $\mathrm{CR}$ 50 steel.

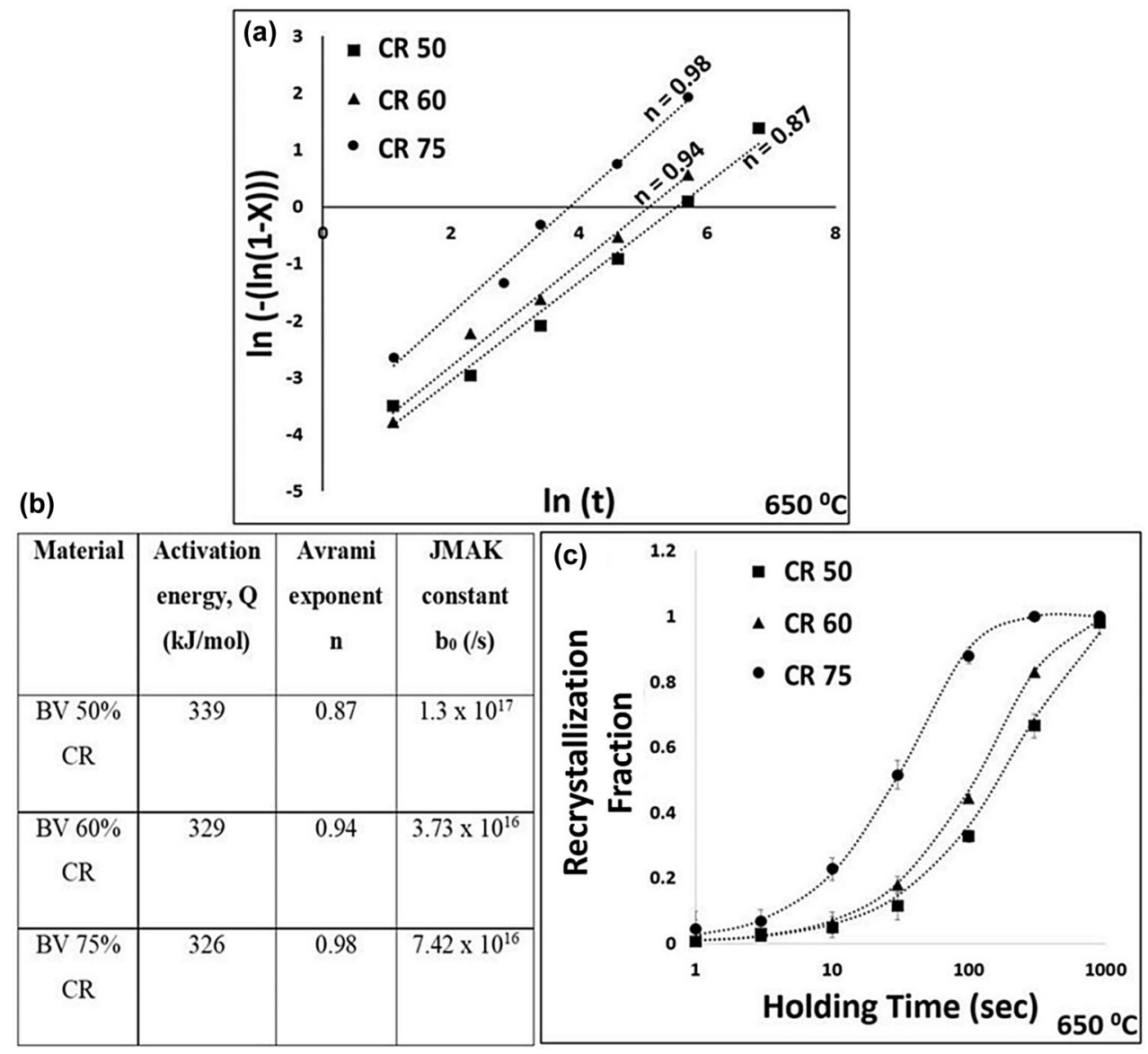

Fig. 5. (a) Linearized JMAK plots for the three different $\mathrm{CR}$ steels at the isothermal holding temperature of $650^{\circ} \mathrm{C}$. (b) JMAK parameters for the three different CR steels. (c) JMAK model fit with the experimental recrystallized values for the three CR steels.

Fig. 5b. It should be noted that the $\mathrm{n}$ value increased and the $\mathrm{Q}$ value decreased with the increase in the CR. This type of decrease in activation energy

of ferrite recrystallization with increase in $\mathrm{CR}$ is well reported in the literature. ${ }^{29}$ Using these parameters, a similar fit between the model and the actual measured values is produced and compared among all the three CRs. This is shown in Fig. 5c for the isothermal holding temperature of $650^{\circ} \mathrm{C}$. 

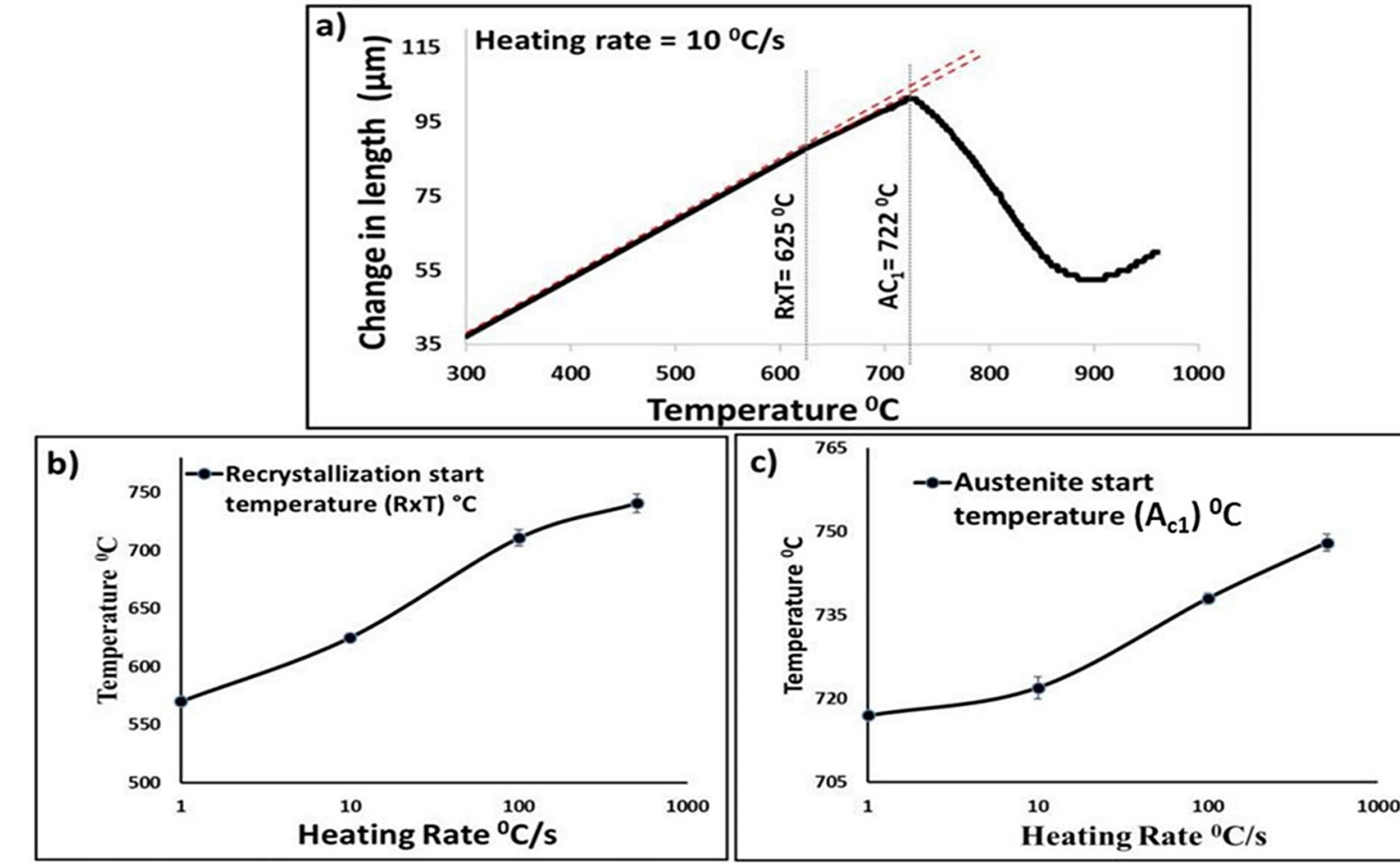

\begin{tabular}{|c|c|c|c|c|c|c|}
\hline \multirow{2}{*}{$\begin{array}{c}\text { Heating Rate } \\
{ }^{0} \mathrm{C} / \mathrm{s}\end{array}$} & \multicolumn{2}{|c|}{ CR $50 \%$} & \multicolumn{2}{|c|}{ CR $60 \%$} & \multicolumn{2}{|c|}{ CR $75 \%$} \\
\hline & $\operatorname{RxT}^{0} \mathrm{C}$ & $\mathrm{AC}_{1}{ }^{0} \mathrm{C}$ & $\operatorname{RxT}^{0} \mathrm{C}$ & $\mathrm{AC}_{1}{ }^{0} \mathrm{C}$ & $\operatorname{RxT}^{0} \mathrm{C}$ & $\mathrm{AC}_{1}{ }^{0} \mathrm{C}$ \\
\hline 1 & 570 & 717 & 560 & 717 & 552 & 717 \\
\hline 10 & 625 & 722 & 610 & 723 & 601 & 723.5 \\
\hline 100 & 711 & 738 & 700 & 740 & 689 & 740 \\
\hline 500 & 741 & 748 & 730 & 749 & 719 & 751 \\
\hline
\end{tabular}

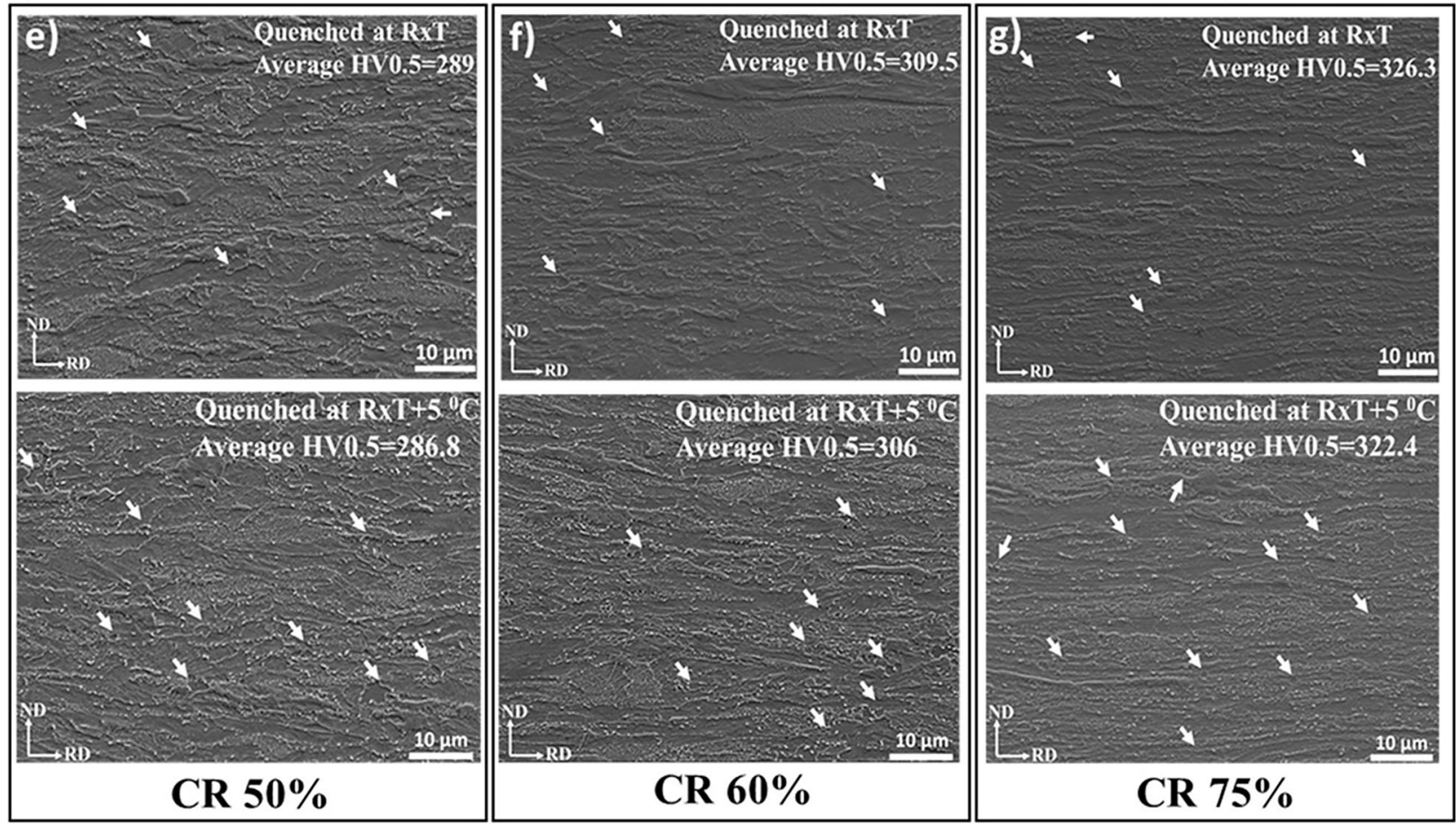


4Fig. 6. (a) Dilation curve for $\mathrm{CR} 50$ steel heated at $10^{\circ} \mathrm{C} / \mathrm{s}$ to complete austenitizing temperature. (b, c) Trend of (b) recrystallization onset temperature and (c) austenite start temperature with respect to the heating rate in CR 50 steel. (d) RxT and $A_{C 1}$ temperatures at various heating rates for the three different CR steels. (e-g) SEM microstructural images of (e) CR 50, (f) CR 60 , and (g) CR 75 steels heated at $10^{\circ} \mathrm{C} / \mathrm{s}$ to RxT and RxT + $5^{\circ} \mathrm{C}$ temperatures.

\section{Prediction of Heating Rate to Obtain a Pre- defined Percentage of Overlap}

Figure $6 \mathrm{a}$ shows the dilation curve obtained from the dilatometer for the CR 50 steel heated at $10^{\circ} \mathrm{C} / \mathrm{s}$ into the austenitic region. Three distinct steps can be identified from this dilation curve. Firstly, the deviation of linearity at $625^{\circ} \mathrm{C}$ can be attributed to the recrystallization start temperature (RxT). This deviation is related to recrystallization-induced plasticity, which is typical for a push-rod type of dilatometer. ${ }^{33}$ According to De Cock et al. ${ }^{34}$ the change in texture during recrystallization can affect this thermal expansion of ferrite grains because of material anisotropy. However, Thomas et al. ${ }^{33}$ found that this deviation cannot be seen in the contact-less laser dilatometer where no stress is applied. Therefore, they concluded that any strain change associated with the recrystallization must involve the application of stress and thereby proposed that recrystallization-induced plasticity was responsible for this change. During recrystallization, the applied stress induced by the push-rod enables directional atomic diffusion ${ }^{35}$ or directional movement of defects, ${ }^{36}$ which can be responsible for this phenomena. To confirm that this deviation from linearity corresponds to the start of recrystallization, interrupted quench tests were carried out for all the CRs heated at $10^{\circ} \mathrm{C} / \mathrm{s}$ to $\mathrm{RxT}$ and $\mathrm{RxT}+5^{\circ} \mathrm{C}$ temperatures obtained from the dilation curves. Figure $6 \mathrm{e}, \mathrm{f}$ and $\mathrm{g}$ shows the microstructures of these samples where nucleation of tiny new recrystallized grains (white arrows) on the elongated ferrite grains can be visible. Moreover, the definite decrease in the hardness values of these samples (compare Fig. 1e) confirms the onset of recrystallization at these corresponding RxT temperatures. Secondly, a sharp drop in the dilation curve at $722^{\circ} \mathrm{C}$ marks the start of austenite formation $\left(\mathrm{A}_{\mathrm{c} 1}\right)$. This contraction is caused because of the crystallographic transformation of $\alpha$ ferrite (BCC) to closepacked $\gamma$ austenite (FCC). Thirdly, the continuous linear increase in the dilation curve indicates the completion of the austenite formation $\left(\mathrm{A}_{\mathrm{c} 3}\right)$. Similar dilation curves were obtained for $1^{\circ} \mathrm{C} / \mathrm{s}, 100^{\circ} \mathrm{C} / \mathrm{s}$, and $500^{\circ} \mathrm{C} / \mathrm{s}$, and their corresponding $\mathrm{RxT}$ and $\mathrm{A}_{\mathrm{c} 1}$ temperatures were recorded, as shown in Fig. $6 \mathrm{~b}$ and c. With the increase in heating rate, both RxT and $\mathrm{A}_{\mathrm{c} 1}$ temperatures increase as both the processes follow thermally activated mechanisms. This increase in $\mathrm{RxT}^{37,38}$ and $\mathrm{A}_{\mathrm{c} 1}{ }^{15}$ temperatures with the increase in heating rate is well documented in the published literature. However, the RxT temperature increases more significantly than the $A_{c 1}$ temperature. Similarly, the RxT and $\mathrm{A}_{\mathrm{c} 1}$ values for the $60 \%$ and $75 \%$ cold-rolled materials were recorded for the same heating rates. These values are shown in Fig. 6d. For a given heating rate, the recrystallization start temperature decreased with the increase in CR. This is due to the increase in the driving force, residual stresses and dislocation density in the highly CR material. ${ }^{39}$ However, for a given heating rate, the amount of CR did not have any significant effect on the $\mathrm{A}_{\mathrm{c} 1}$ temperatures.

In order to determine the fraction of recrystallization at the onset of austenite formation for a particular heating rate, a continuous heating rate model has been developed by modifying the JMAK law from Eq. 2.

Firstly, Eq. 2 is differentiated with respect to time and a first-order differential equation is obtained as shown in Eq. 5.

$$
\frac{\mathrm{d} X}{\mathrm{~d} t}=b n \exp ^{-b t^{n}} t^{n-1}=b n(1-X) t^{n-1}
$$

Secondly, Eq. 5 is integrated with respect to time to obtain a relationship between the recrystallization fraction and time in the integration form as shown below in Eq. 6 .

$$
\ln (1-X)=-n \int_{0}^{t} b t^{n-1} \mathrm{~d} t
$$

Thirdly, heating rate (H.R.) is defined as the change in temperature from the recrystallization start temperature (RxT) with respect to time. Here, the continuous recrystallization kinetics was calculated using the additive principle ${ }^{40-42}$ where the increase in temperature due to continuous heating is sub-divided into infinitesimally small isothermal soaking times, as shown in Eq. 7.

$$
\text { H.R. }=\frac{T-R \times T}{t} \Rightarrow \mathrm{d} t=\frac{\mathrm{d} T}{\mathrm{H} . \mathrm{R} .}
$$

Fourthly, the integrated JMAK law (Eq. 6) is further rearranged and Eq. 7 is substituted into it to obtain the following relationship, represented by Eq. 8.

$$
X=1-\exp ^{-n} \int_{R \times T}^{T} b \frac{(T-R \times T)^{n-1} \mathrm{~d} T}{\mathrm{H} \cdot \mathrm{R}^{n-1} \mathrm{H} \cdot \mathrm{R} .}
$$

Finally after rearranging Eq. 8 with the substitution of $b$ value from Eq. 3, an equation is developed which determines the fraction of recrystallization taking place before the austenite formation for a particular heating rate, which is represented by Eq. 9 . 
Table I. Recrystallization fraction before austenite formation for all the three CRs with respect to the heating rate employed

\begin{tabular}{lccc}
\hline & \multicolumn{3}{c}{ Recrystallization fraction before austenite formation } \\
\cline { 2 - 5 } Heating rate & $\mathbf{C R ~ 5 0}$ & $\mathbf{C R ~ 6 0}$ & $\mathbf{C R} \mathbf{7 5}$ \\
\cline { 2 - 5 } $1{ }^{\circ} \mathrm{C} / \mathrm{s}$ & 0.82 & 0.92 & 1.00 \\
$10^{\circ} \mathrm{C} / \mathrm{s}$ & 0.265 & 0.316 & 0.73 \\
$100^{\circ} \mathrm{C} / \mathrm{s}$ & 0.07 & 0.075 & 0.22 \\
$500^{\circ} \mathrm{C} / \mathrm{s}$ & 0.012 & 0.017 & 0.06 \\
\hline
\end{tabular}

$$
X=1-\exp \left\{-\frac{b_{0} n}{\mathrm{H} \cdot R^{n}} \int_{R \times T}^{T} \exp \left(\frac{-Q}{R T}\right)\left[(T-R \times T)^{n-1}\right] \mathrm{d} T\right\}
$$

The fraction of recrystallization values before the start of austenite formation was calculated for the various heating rates for all CRs and is shown in Table I. The RxT and $A_{c 1}$ values required for the numerical integration part were taken from Fig. $6 \mathrm{~d}$.

The fraction of recrystallization at the onset of austenite formation is found to be decreasing with increased heating rates for all the CRs. This is due to the fact that the time available for the nucleation and growth of the new strain-free grains will be drastically decreased as the heating rate increases. Moreover, the mobility of the ferrite grains will be sluggish at higher heating rates as the iron atoms require a minimum incubation time to undergo diffusion process. It can also be seen that the degree of recrystallization before austenite formation increases significantly with the increase in CR for any particular heating rate. This is because of faster recrystallization kinetics with increases in CR due to the availability of higher stored energy in the CR material. For instance, at $10^{\circ} \mathrm{C} / \mathrm{s}$, recrystallization is only $26 \%$ complete before the onset of austenite formation in CR 50 material, whereas recrystallization is already $73 \%$ complete in CR 75 material. This means that, in higher CR steels, only a fraction of ferrite grains will be available to recrystallize simultaneously with the austenite formation step. This also implies that heating rates need to be extremely high for CR 60 and CR 75 materials in order to achieve high percentages of overlap between ferrite recrystallization and austenite formation. For instance, Petrov et al. concluded that heating rates higher than $1000^{\circ} \mathrm{C} / \mathrm{s}$ are required for complete overlap to occur in $95 \%$ CR ferrite-pearlite steels. ${ }^{43}$ In this regard, among the three CRs in the study, CR 50 material was considered to produce maximum overlap under industrially relevant heating rates. Moreover, the $\mathrm{RxT}$ and $\mathrm{A}_{\mathrm{c} 1}$ values shown in Fig. 6d will be very difficult to determine at extremely high rates because of the limited sensitivity of dilation change measured in the dilatometer. To determine the heating rates required for a predefined amount of overlap in the CR 50\% material, Eq. 9 has been re-arranged as Eq. 10.

$$
\% \text { Overlap }=\exp \left\{-\frac{b_{0} n}{H \cdot R^{n}} \int_{R x T}^{T} \exp \left(\frac{-Q}{R T}\right)\left[(T-R x T)^{n-1}\right] d T\right\}
$$

Using the RxT and $A_{c 1}$ temperature trends from Fig. 6, the above continuous heating rate model was used to determine the specific heating rates required for $1 \%, 15 \%, 34 \%, 67 \%, 88 \%$ and $99 \%$ overlap in the CR 50\% material. These values are shown in Fig. 7a. According to the model, to achieve a $100 \%$ complete overlap between the ferrite recrystallization and the austenite formation, extreme heating rates higher than $511^{\circ} \mathrm{C} / \mathrm{s}$ is needed to be employed for this material. However, these extreme heating rates are almost impossible to achieve by present-day industrial routes. Steel industries which use radiant tube furnaces cannot produce heating rates more than $10^{\circ} \mathrm{C} / \mathrm{s}$, whereas the industries with direct tube furnaces can induce heating rates just above $50^{\circ} \mathrm{C} / \mathrm{s} .{ }^{44}$ Therefore, in present-day industrial routes, a maximum overlap of $\sim 88 \%$ can be achieved for this CR 50 material. It should also be noted that this amount of overlap decreases with the increase in CR for the same material. In order to validate the model, the samples were continuously heated to below $\mathrm{A}_{\mathrm{c} 1}$ temperatures at the predicted heating rates, followed by quenching to room temperature. Figure $7 b, c, d$ and e shows the EBSD inverse pole figures (IPF) of the continuously heattreated samples, heated at predicted heating rates of $0.2^{\circ} \mathrm{C} / \mathrm{s}, 0.9^{\circ} \mathrm{C} / \mathrm{s}, 7^{\circ} \mathrm{C} / \mathrm{s}$ and $50.5^{\circ} \mathrm{C} / \mathrm{s}$, respectively. It can be clearly seen that completely equi-axed recrystallized grains are formed in the sample heated at $0.2^{\circ} \mathrm{C} / \mathrm{s}$. Similarly, the sample heated at $0.9^{\circ} \mathrm{C} / \mathrm{s}$ has a majority of recrystallized grains containing a small fraction of non-recrystallized grains. As expected, with the increase in the heating rate, the number of recrystallized grains decreased and the cold-rolled texture in the material is retained. In other words, the amount of recrystallization and the size of recrystallized grains 


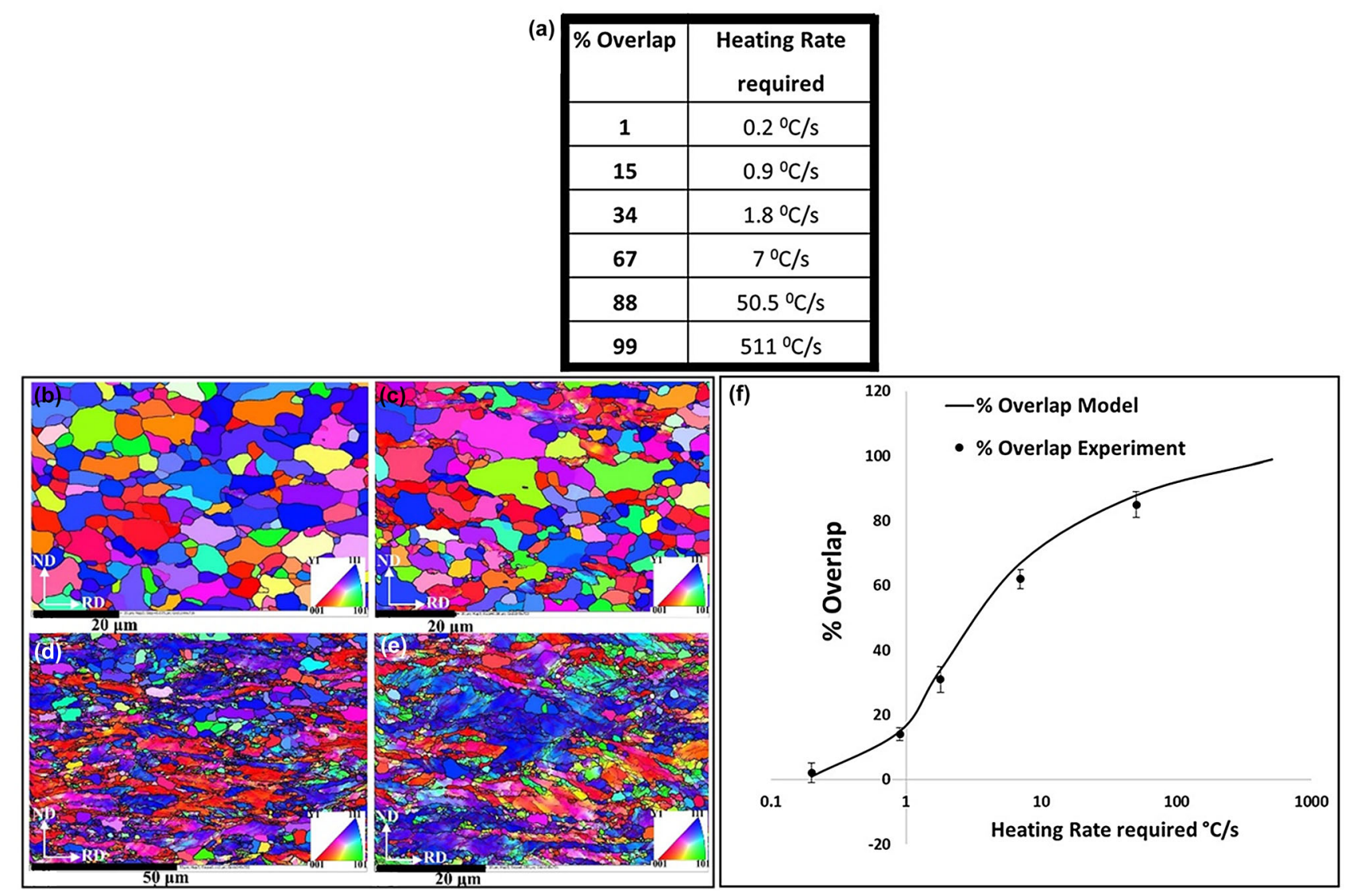

Fig. 7. (a) Predicted heating rates for a predefined amount of overlap in CR 50 steel. (b-e) EBSD IPF images of CR 50 steels heat-treated to respective $A_{c 1}$ below temperature at heating rates of (b) $0.2^{\circ} \mathrm{C} / \mathrm{s}$, (c) $0.9^{\circ} \mathrm{C} / \mathrm{s}$, (d) $7^{\circ} \mathrm{C} / \mathrm{s}$, and (e) $50.5^{\circ} \mathrm{C} / \mathrm{s}$. (f) Comparison of model predicted and experimentally evaluated $\%$ overlap values with respect to the heating rates employed.

decreased significantly with the increase in the heating rate. This is because the recrystallization start temperature $(\mathrm{RxT})$ increases with increasing heating rate and, moreover, the time available for the growth of recrystallized grains decreases with the increase in heating rate. ${ }^{45}$ Figure $7 \mathrm{f}$ shows the experimentally evaluated overlap values at the predicted heating rates. It can be clearly seen that the model matches the experimental values at lower heating rates. However, the model slightly underpredicts the heating rates required for the higher amount of overlap to occur. Nevertheless, the developed model can be successfully used in both industrial applications and academic research in predicting heating rates for various initial microstructures and chemical compositions in DP steel manufacturing.

\section{CONCLUSION}

1. JMAK parameters were determined for three different CR low-carbon steels. A modified JMAK model was found to be in good agreement with experimentally determined recrystallization fractions for all the CRs.
2. The recrystallization kinetics was found to be increased with increases in isothermal holding temperature and cold-rolling reduction.

3. The higher driving force in higher cold-rolling reduction resulted in higher recrystallization kinetics and thereby increased the percentage of recrystallization occurring before austenite formation.

4. Both RxT and $A_{c 1}$ temperatures were found to be increased with increases in the heating rates for all the CR steels.

5. A continuous heating rate model which predicts the heating rate required for a predefined amount of overlap was successfully generated.

6. With the increase in heating rate, the percentage of recrystallization occurring before austenite formation was found to decrease.

7. The modified JMAK equation predicts that an extreme heating rate over $500^{\circ} \mathrm{C} / \mathrm{s}$ is required for $100 \%$ overlap between ferrite recrystallization and austenite formation in CR 50 steel.

8. The developed model, based on the modified JMAK equations, allows the predicting of heating rates to achieve identical overlaps for different initial microstructures with varying compositions, and therefore can help in developing a systematic comparison of microstructure evolution in the DP steel manufacture. 


\section{OPEN ACCESS}

This article is distributed under the terms of the Creative Commons Attribution 4.0 International License (http://creativecommons.org/licenses/by/4.0/), which permits unrestricted use, distribution, and reproduction in any medium, provided you give appropriate credit to the original author(s) and the source, provide a link to the Creative Commons license, and indicate if changes were made.

\section{REFERENCES}

1. J.N. Hall and J.R. Fekete, in Automotive Steels: Design, Metallurgy, Processing and Applications (Elsevier, 2016), pp. $19-45$

2. A. Bag, K.K. Ray, and E.S. Dwarakadasa, Metall. Mater. Trans. A Phys. Metall. Mater. Sci. 32, 2207 (2001).

3. M. Adhikary, A. Chakraborty, A. Das, T. Venugopalan, and R. Kumar, Mater. Sci. Eng. A 736, 209 (2018).

4. N. Fonstein, in Automotive Steels (Elsevier, 2017), pp. 169216.

5. M. Mazinani and W.J. Poole, Metall Mater Trans A Phys Metall Mater Sci 38, 328 (2007).

6. N. Fonstein and A.N. Bortsov, Fiz. Met. Met. 61, 289 (1986).

7. R.G. Davies, Met. Trans. A 9A, 451 (1978).

8. C.P. Scott, F. Fazeli, B. Shalchi Amirkhiz, I. Pushkareva, and S.Y.P. Allain, Mater. Sci. Eng. A 703, 293 (2017).

9. D.A. Korzekwa, D.K. Matlock, and G. Krauss, Metall. Trans. A 15, 1221 (1984).

10. H. Azizi-Alizamini, M. Militzer, and W.J. Poole, Metall. Mater. Trans. A Phys. Metall. Mater. Sci. 42, 1544 (2011).

11. J. Huang, W.J. Poole, and M. Militzer, Metall. Mater. Trans. A Phys. Metall. Mater. Sci. 35A, 3363 (2004).

12. C.C. Tasan, M. Diehl, D. Yan, M. Bechtold, F. Roters, L. Schemmann, C. Zheng, N. Peranio, D. Ponge, M. Koyama, K. Tsuzaki, and D. Raabe, Annu. Rev. Mater. Res. 45, 391 (2015)

13. Y.Y. Meshkov and E.V. Pereloma, in Phase Transformations in Steels (2012), pp. 581-618.

14. A.C.C. Reis, L. Brackie, R. Petrov, W.J. Kaluba, Y. Houbaert, and L. Kestens, ISIJ Int. 43, 1260 (2003).

15. D. De Knijf, A. Puype, C. Föjer, and R. Petrov, Mater. Sci. Eng. A 627, 182 (2015).

16. V. Massardier, A. Ngansop, D. Fabrègue, and J. Merlin, Mater. Sci. Forum 638-642, 3368 (2010).

17. R. Rocha and T. Melo, Mater. Sci. 391, 296 (2005).

18. N. Peranio, F. Roters, and D. Raabe, Mater. Sci. Forum 715716, 13 (2012).

19. F.C. Cerda, C. Goulas, I. Sabirov, S. Papaefthymiou, A. Monsalve, and R.H. Petrov, Mater. Sci. Eng. A 672, 108 (2016).

20. R. Petrov, F. Hajyakbari, F.R. Saz, J. Sidor, M.J. Santofimia, J. Sietsma, and L.A.I. Kestens, Mater. Sci. Forum 753 554 (2013).
21. T. Lolla, G. Cola, B. Narayanan, B. Alexandrov, and S.S. Babu, Mater. Sci. Technol. 27, 863 (2011).

22. M. Bellavoine, M. Dumont, J. Drillet, V. Hébert, and P. Maugis, Metall. Mater. Trans. A Phys. Metall. Mater. Sci. 49, 2865 (2018).

23. C. Philippot, M. Bellavoine, M. Dumont, K. Hoummada, J. Drillet, V. Hebert, and P. Maugis, Metall. Mater. Trans. A Phys. Metall. Mater. Sci. 49, 66 (2018).

24. V. Massardier, A. Ngansop, D. Fabregue, S. Cazottes, and J. Merlin, Metall. Mater. Trans. A Phys. Metall. Mater. Sci. 43, 2225 (2012).

25. M. Kulakov, W.J. Poole, and M. Militzer, Metall. Mater. Trans. A Phys. Metall. Mater. Sci. 44, 3564 (2013).

26. F.J. Humphreys and M. Hatherly, Recrystallisation and Related Annealing Phenomena (2004).

27. E.A. Simielli, S. Yue, and J.J. Jonas, Metall. Trans. A 23, 597 (1992).

28. I. Nikitin and M. Besel, Scr. Mater. 58, 239 (2008).

29. D.Z. Yang, E.L. Brown, D.K. Matlock, and G. Krauss, $M e$ tall. Trans. A 16, 1385 (1985).

30. P. Li, J. Li, Q. Meng, W. Hu, and D. Xu, J. Alloys Compd. 578, 320 (2013).

31. R.A. Oriani, Acta Metall. 12, 1399 (1964).

32. H. Hu and S.R. Goodman, Metall. Trans. 1, 3057 (1970).

33. L.S. Thomas, K.D. Clarke, and D.K. Matlock, in Proceedings of the 6th International Conference on Recrystallization and Grain Growth (2016), pp. 91-96.

34. T. De Cock, C. Capdevila, F.G. Caballero, and C.G. De Andrés, Scr. Mater. 54, 949 (2006).

35. H.N. Han, S.J. Kim, M. Kim, G. Kim, D.W. Suh, and S.J. Kim, Philos. Mag. 88, 1811 (2008).

36. E.I. Estrin, Phys. Met. Metallogr. 102, 324 (2006)

37. M. Atkinson, Mater. Sci. Eng. A Struct. Mater. Prop. Microstruct. Process 262, 33 (1999).

38. M. Ferry, D. Muljono, and D.P. Dunne, ISIJ Int. 41, 1053 (2001).

39. V. Raghavan, Physical Metallurgy: Principles and Practice (Prentice Hall of India Pvt. Ltd, New Delhi, India, 2015), pp. $65-99$.

40. M. Lusk and H.J. Jou, Metall. Mater. Trans. A Phys. Metall. Mater. Sci. 28, 287 (1997).

41. K. Mukunthan and E.B. Hawbolt, Metall. Mater. Trans. A Phys. Metall. Mater. Sci. 27, 3410 (1996).

42. L.S. Thomas and D.K. Matlock, Metall. Mater. Trans. A Phys. Metall. Mater. Sci. 49, 4456 (2018).

43. R.H. Petrov, J.J. Sidor, and L.A.I. Kestens, Mater. Sci. Forum 702-703, 798 (2011).

44. R.R. Mohanty, O.A. Girina, and N.M. Fonstein, Met Mater Trans A Phys Met Mater Sci 42, 3680 (2011).

45. D. Muljono, M. Ferry, and D.P. Dunne, Mater. Sci. Eng. A $303,90(2001)$

Publisher's Note Springer Nature remains neutral with regard to jurisdictional claims in published maps and institutional affiliations. 